\title{
Clinical and Economic Benefits of Upper Airway Stimulation for Obstructive Sleep Apnea in a European Setting
}

\author{
Jan Benjamin Pietzsch ${ }^{a}$ Ann-Kathrin Richter ${ }^{b}$ Winfried Randerath ${ }^{c}$ \\ Armin Steffen $^{d}$ Shan Liu ${ }^{a, e}$ Benjamin P. Geisler ${ }^{a, f}$ Jürgen Wasem ${ }^{b}$ \\ Janine Biermann-Stallwitz ${ }^{b, g}$ \\ ${ }^{a}$ Wing Tech Inc., Menlo Park, CA, USA; ${ }^{b}$ Institute for Health Care Management and Research, University of \\ Duisburg-Essen, Essen, Germany; ${ }^{C}$ Department of Pneumology and Allergology, Bethanien Hospital, Solingen,

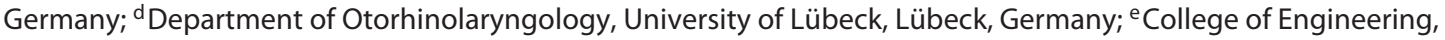 \\ University of Washington, Seattle, WA, USA; ${ }^{\mathrm{f}}$ Department of Medicine, Massachusetts General Hospital/Harvard \\ Medical School, Boston, MA, USA; ${ }^{9}$ Essener Forschungsinstitut für Medizinmanagement - EsFoMed GmbH, Essen, \\ Germany
}

\section{Keywords}

Upper airway stimulation · Implantable pulse generator · Obstructive sleep apnea · Sleep apnea · Markov model · Decision support techniques - Cost-effectiveness analysis · Cost-benefit analysis

\begin{abstract}
Background: Upper airway stimulation (UAS) is a treatment approach for patients with moderate-to-severe obstructive sleep apnea who cannot adhere to continuous positive airway pressure therapy. Objective: The objective was to evaluate added patient benefit and cost-effectiveness of UAS in the German health care system. Methods: We used a decision-analytic Markov model to project major adverse cardiovascular or cerebrovascular events (myocardial infarction [MI] or stroke), motor vehicle collision (MVC), mortality, quality-adjusted life years (QALYs), and costs. The assumed reduction in the apnea-hypopnea index with UAS compared to no treatment is based on German real-world data. Other input data were derived from the literature, public statistics, and multivariate regression. Cost-effectiveness was evalu-
\end{abstract}

ated in Euros per QALY gained, both discounted at 3\%. Results: UAS was projected to reduce event risks (10-year relative risk for stroke, $\mathrm{MI}$, cardiovascular death, and MVC: $0.76,0.64,0.65$, and 0.34 , respectively), and to increase survival by 1.27 years. While the UAS strategy incurred an additional 1.02 QALYs within the patient lifetime, there were also additional costs of EUR 45,196, resulting in an incremental cost-effectiveness ratio of EUR 44,446 per QALY gained. Conclusions: In the present model-based analysis, UAS therapy provides meaningful benefit to patient-relevant endpoints and is a cost-effective therapy in the German setting.

(c) 2019 S. Karger AG, Basel

\section{Introduction}

Obstructive sleep apnea (OSA) is a condition characterized by frequent interruption in breathing due to collapsing pharyngeal soft tissue while asleep $[1,2]$. Gender-

J.B. Pietzsch and A.-K. Weschenfelder contributed equally to this study and share joint first authorship.

\section{KARGER}

(c) 2019 S. Karger AG, Basel

E-Mail karger@karger.com

www.karger.com/res
Jan Benjamin Pietzsch

Wing Tech Inc.

101 Jefferson Drive

Menlo Park, CA 94025 (USA)

E-Mail jpietzsch@wing-tech.com 
and age-specific prevalence of moderate-to-severe OSA, as defined by an apnea-hypopnea index (AHI) of $\geq 15$ events/h), has been estimated to range from 3 to $17 \%[3,4]$.

OSA is a risk factor for several cardiovascular, neurologic, as well as metabolic conditions and is associated with increased daytime sleepiness and reduced health-related quality of life $[3,5,6]$. Importantly, OSA-related increases in daytime sleepiness have been shown to be associated with increased risks of motor vehicle collisions (MVCs) and other accidents, which pose particularly high risks for professional drivers and other high-risk professions [5].

To improve quality of life and avoid or reduce adverse consequences of OSA, several therapies are available in routine clinical practice: In mild-to-moderate disease, OSA treatments include dental appliances, positional therapy, and continuous positive airway pressure (CPAP). In moderate-to-severe OSA, CPAP is recommended as first-line therapy and continues to be the mainstay treatment approach [7]. Anatomy-altering surgical interventions can be considered in selected cases. If adhered to, CPAP decreases or even eliminates daytime sleepiness and adverse events associated with OSA. However, nonfitted masks, difficult anatomies, adverse events, or (more commonly) the discomfort of wearing the mask and being ventilated lead to suboptimal adherence, resulting in reduced treatment effectiveness. Previous studies have estimated that adherence to CPAP ranges from 50 to $90 \%$ in European countries [8].

For individual patients who are either ineligible for CPAP or mandibular advancement devices or show insufficient treatment efficacy, upper airway stimulation (UAS) has recently emerged as a more viable treatment alternative and has been adopted in clinical practice [7]. This treatment approach involves unilateral respirationsynchronized stimulation of the hypoglossal nerve through surgical placement of an implantable pulse generator, a breathing sensor, and a stimulation electrode placed on the hypoglossal nerve. UAS has been shown to safely and effectively maintain airway patency in controlled clinical trials when certain physiological and anatomical criteria are met [9-11]. One of the major selection criteria for therapy response is the absence of a complete concentric collapse in drug-induced sleep endoscopy [12], which is seen in about a fifth of second-line treatment-seeking patients in a German cohort [13].

In the multicenter prospective observational STAR study conducted in the United States, UAS with the Inspire system (Inspire Medical Systems, Inc., Minneapolis,
MN, USA) was shown to reduce the AHI by $68 \%$ from 29.3 to 9.0 events per hour at the 12 -month follow-up $(p<0.001)$ and to clinically meaningful reductions in daytime sleepiness and increase patients' health-related quality of life [9]. These reductions in disease severity and improvements in quality of life were sustained at the 3and 5-year follow-ups [10]. Comparable data confirming the safety and effectiveness of the Inspire system at the 12 -month follow-up in a real-world setting were recently reported by a prospective German multicenter study $(n=$ 60) $[11,14]$.

As UAS therapy may involve high upfront investment, long-term outcomes with regard to clinical benefits and cost-effectiveness are of relevance for patients, physicians, and health care systems. A previous health-economic model, projecting costs and outcomes based on the 12-month data from the STAR study, found UAS to be cost-effective in the US context [15].

The objective of the current study was to estimate the long-term clinical benefit as well as the cost-effectiveness of UAS in a German patient cohort.

\section{Materials and Methods}

Study Design

A decision-analytic modeling framework projected 10-year and lifetime clinical outcomes and costs of UAS therapy compared to no therapy based on recently published cohort characteristics and effectiveness data from the recent German post-market study [14].

\section{Methods}

The model adopted the structure of a previously published Markov model that has been used to investigate the effect of different diagnostic and therapeutic OSA strategies [15]. In brief, this model is comprised of 5 health states and tracks the occurrence of stroke, myocardial infarction (MI), MVC, and death based on multivariate risk equations. To account for different mortality risks and costs after the tracked cardiovascular events, the model includes post-stroke and post-MI states. Schematic representations of the model can be found in Figure 1 and the supplementary material (for all online supplementary material, see www. karger.com/doi/10.1159/000497101).

We populated this model with incidence and prevalence data from the German setting, relying on systematic literature searches to identify parameter data. Wherever available, data for Germany were used; these included lifetables, MI and stroke incidence, prevalence of hypertension, and baseline risks of MVCs. Where German data were not available, inputs from other European or global settings were used to complement the data, as appropriate. Table 1 summarizes key model inputs (see also supplementary material).

Cohort characteristics were based on the German prospective observational study [11] and included a predominantly male population at an average age of 57 years at the time of UAS index treat- 


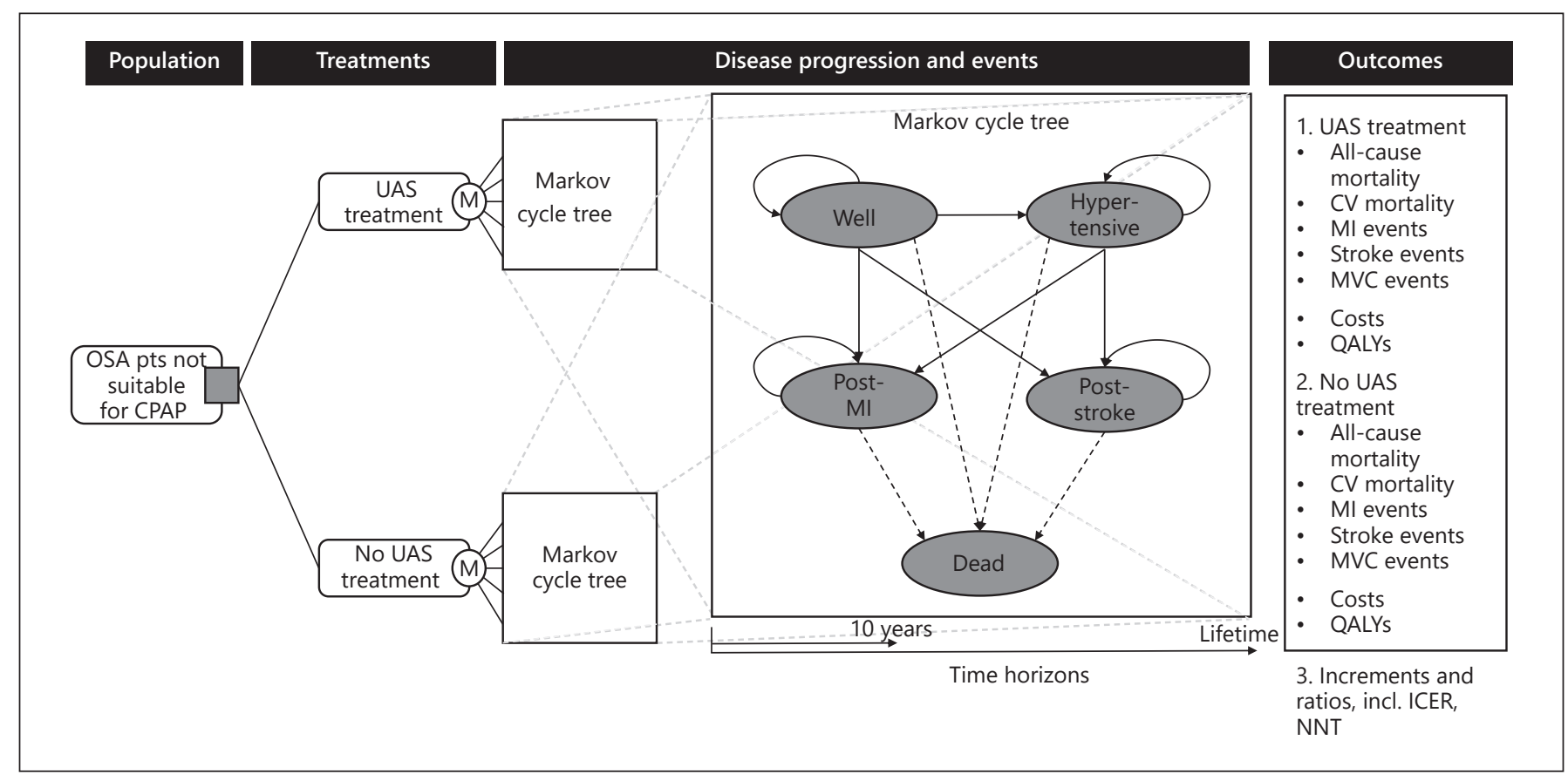

Fig. 1. Schematic representation (simplified) of the model structure, a combination of decision tree and a Markov model. CPAP, continuous positive airway pressure; MI, myocardial infarction; MVC, motor vehicle collision; NNT, number needed to treat; OSA, obstructive sleep apnea; QALY, quality-adjusted life year; UAS, upper airway stimulation.

ment. In that study, the mean baseline AHI of 31.2 events per hour was reduced to 13.8 events per hour within 12 months [14].

In line with the previously published model [15], we performed multivariate linear regression to determine cardiovascular event risks associated with different AHI levels, relying on data from a European cohort study that followed CPAP-treated and non-CPAP-treated patients with different OSA severity over 10 years [16]. AHI was used as it was previously observed that lower AHI levels were associated with a better prognosis. We defined the subset of snorers (AHI of 3.5) as representative for the general population mortality and computed hazard ratios of cardiovascular events associated with AHI rates of 13.8 and 31.2 events per hour, compared to baseline 3.5 [14]. These hazard ratios were multiplied with the baseline event rates for the general population to obtain AHI-adjusted cardiovascular event rates. Based on the regression analysis, we obtained an estimated UASassociated cardiovascular event risk reduction of $75 \%$. This estimate was further multiplied by the percentage of daily UAS use (81\%) reported at the 3-year follow-up in the STAR study [10]. Thus, the estimated effective cardiovascular event risk reduction was $61 \%$ (i.e., a $61 \%$ reduction in the OSA-associated excess risk) (Table 1; online suppl. material).

MVC event risk in effectively treated patients was assumed to be similar to the general population risk, whereas a threefold increased risk was assumed in untreated patients $[17,18]$.

For the base case analysis, therapy effectiveness was assumed to be maintained over the patient's remaining lifetime, assuming a constant percentage of daily UAS use. This assumption is support- ed by the long-term UAS effectiveness observed at the 5-year follow-up in the STAR study [10].

Health state-specific utility estimates were based on values from the published literature and ranged from 0.63 for patients after stroke to 1.0 for patients at non-elevated AHI level without symptoms or other cardiovascular morbidity before age adjustment (Table 1).

The UAS treatment costs included pretreatment examinations, device costs, inpatient hospital stay for device implantation, activation, and titration, as well as annual follow-up outpatient visits (Table 1; online suppl. material). In line with the current product documentation, a mean battery lifetime of 11 years was assumed, at which time replacement of the implantable pulse generator is required.

In the model, acute costs for MI, stroke, and MVC events were considered as well as health state-specific costs which were comprised of age-dependent general health care costs applying to each patient alive and additional condition-specific costs for hypertension and states after MI and stroke. All costs were derived from published literature and public statistics and, if appropriate, adjusted to reflect current German clinical practice (Table 1; online suppl. material). The harmonized German general consumer price index was used to adjust all costs to reflect 2016 Euro values.

\section{Analysis}

For both treatment strategies in the model, we computed event rates (MI, stroke, MVC, and cardiovascular disease [CVD] mortality), unadjusted and quality-adjusted survival, and costs. Primary outcomes were 10-year and lifetime-relative event risks, numbers needed to treat (NNT), and unadjusted and quality-adjusted survival gain. 
Table 1. Model input parameters

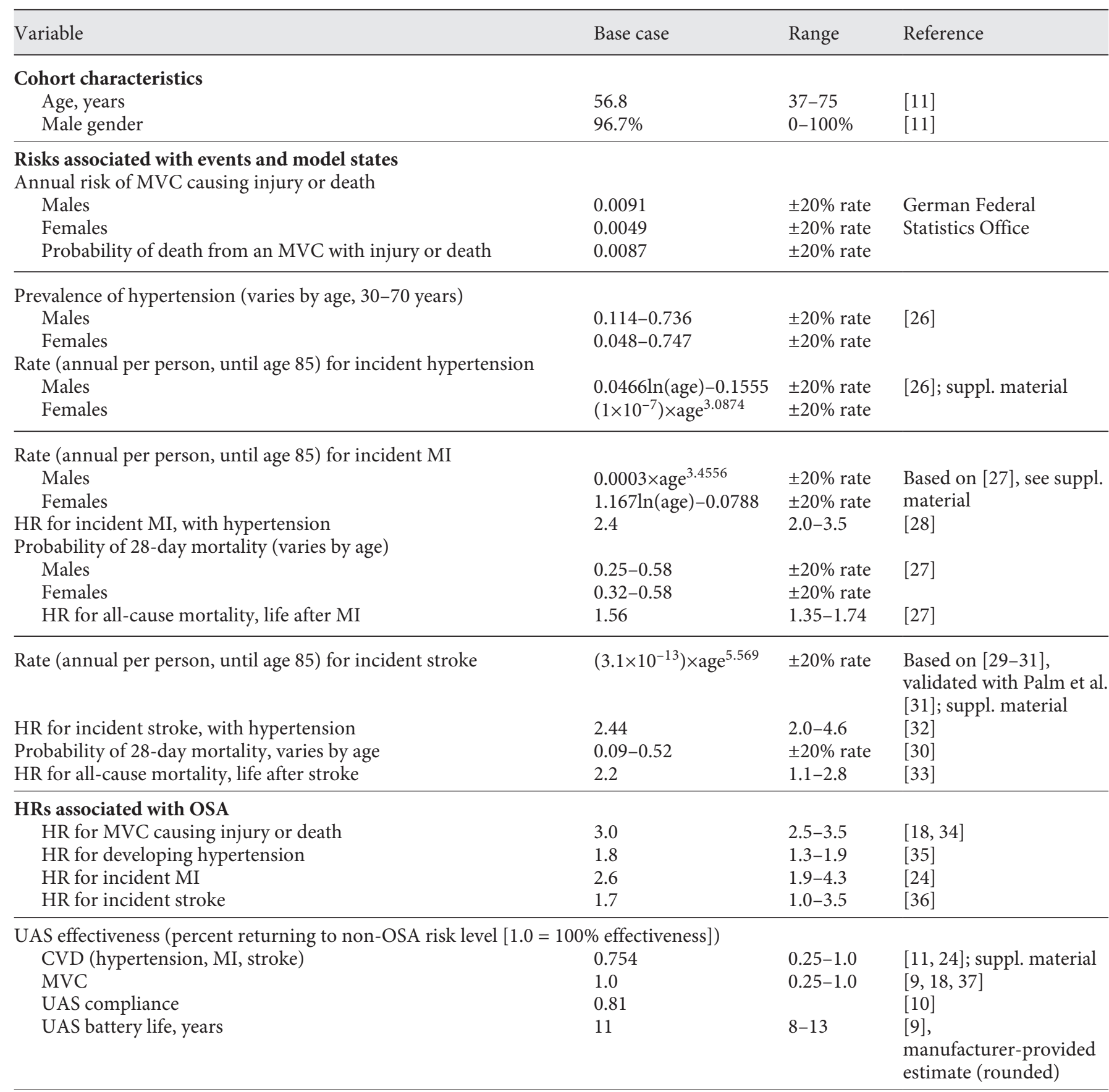

Cost-effectiveness was evaluated based on the incremental cost-effectiveness ratio (ICER), measured in terms of cost difference divided by difference in quality-adjusted life years (QALYs), both of which were discounted at $3 \%$ p.a., as recommended in current guidelines for cost-effectiveness analysis [19]. In the absence of published willingness-to-pay thresholds for Germany, we followed WHO recommendations, where an intervention with an
ICER at $<1$ time per capita gross domestic product (GDP) is considered highly cost-effective and at $<3$ times per capita GDP costeffective [20]. The German per capita GDP in 2016 was EUR $37,866[21]$.

One-way deterministic sensitivity analyses were performed based on the parameter ranges given in Table 1 to evaluate the effect of parameter uncertainty on the cost-effectiveness results. 
Table 1 (continued)

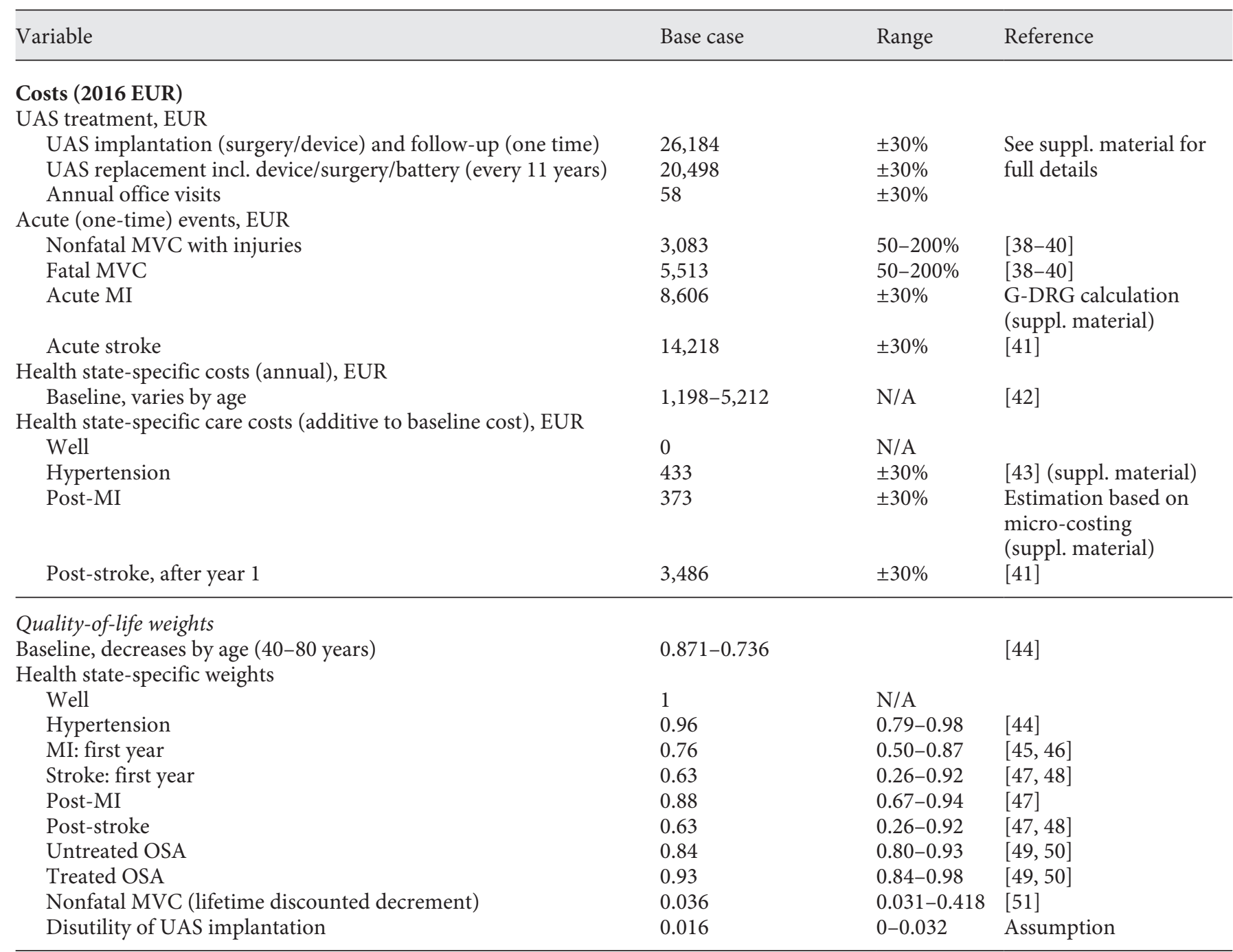

CVD, cardiovascular disease; G-DRG, German Diagnosis-Related Group; HR, hazard ratio; MI, myocardial infarction; MVC, motor vehicle collision; OSA, obstructive sleep apnea; UAS, upper airway stimulation.

\section{Results}

The projected event risk reduction for UAS treatment over a 10 -year period was $24 \%$ for stroke ( $0.058 \mathrm{vs.} 0.076$ ), $36 \%$ for MI ( 0.111 vs. 0.173$)$, and $66 \%$ for MVC ( 0.083 vs. 0.0246). Cardiovascular death and all-cause death were reduced by $35 \%(0.053$ vs. 0.082$)$ and $15 \%$ ( 0.165 vs. $0.195)$, respectively, in 10 years. Resulting NNTs to avoid 1 event ranged from 6.2 for MVC to 55.6 for stroke (Fig. 2; online suppl. material).

Over the lifetime horizon, relative event risk reduction ranged from $64 \%$ for MVC events ( 0.182 vs. 0.512$)$ to $4 \%$
( 0.243 vs. 0.254$)$ for stroke. Associated NNTs varied between 3 patients for MVC events and 91 for stroke (Fig. 2; online suppl. material). The survival benefit for UAStreated patients compared to untreated patients was 1.27 life years with life expectancy increasing from 19.14 to 20.41 years. The undiscounted gain in QALYs is 1.56 QALYs based on an increase from 12.15 to 13.71 QALYs during the patient's lifetime.

For the lifetime projection, UAS treatment was costeffective compared to no treatment at an ICER of EUR 44,446 per QALY (Table 2). Projecting costs and QALYs over a 10 -year period resulted in a slightly higher ICER of
42
Pietzsch et al. 
Fig. 2. Absolute event rates and number needed to treat (NNT) of clinical events for a 10 -year time horizon (see supplementary material for details as well the for the lifetime analysis). CV, cardiovascular; MI, myocardial infarction; MVC, motor vehicle collision; UAS, upper airway stumulation

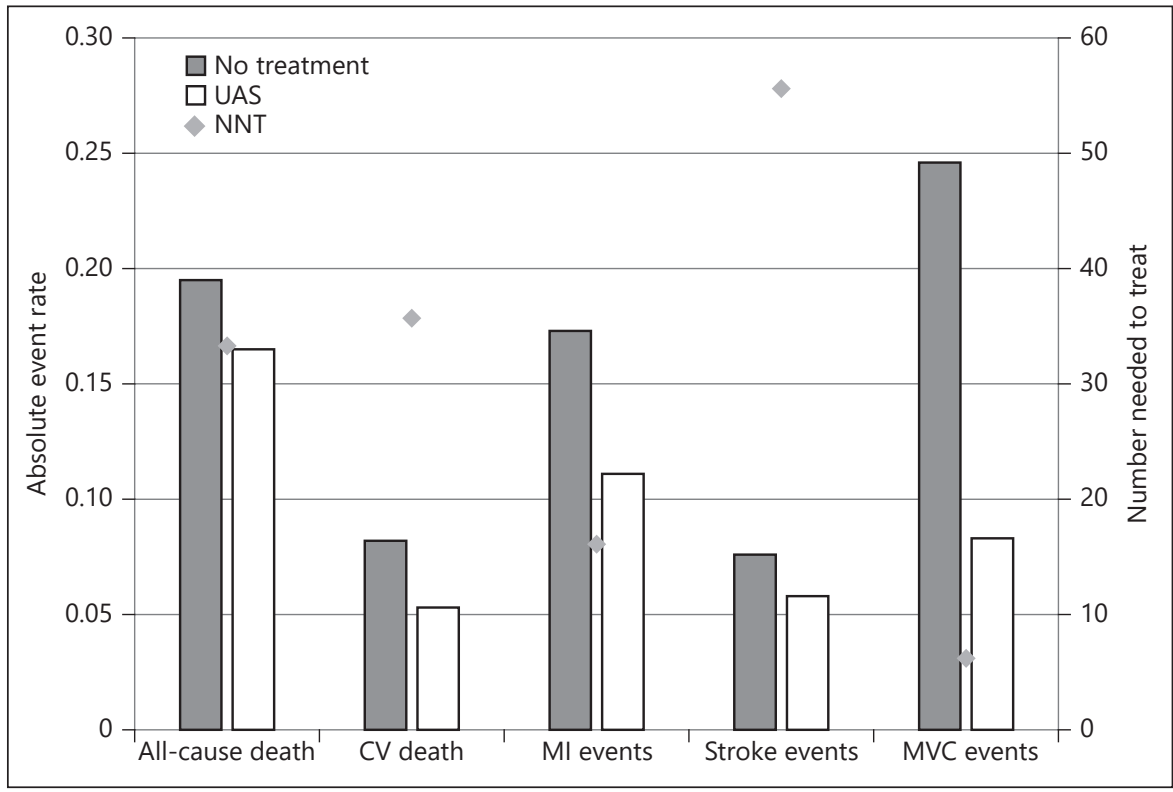

Table 2. Total and incremental costs and quality-adjusted life years (QALYs) for a lifetime and 10-year time horizon

\begin{tabular}{llllll}
\hline Treatment strategy & $\begin{array}{l}\text { Total costs } \\
\text { EUR }\end{array}$ & $\begin{array}{l}\text { Total } \\
\text { QALYs }\end{array}$ & $\begin{array}{l}\text { Difference } \\
\text { in costs }\end{array}$ & $\begin{array}{l}\text { Difference } \\
\text { in QALYs }\end{array}$ & $\begin{array}{l}\text { ICER, EUR/ } \\
\text { QALY }\end{array}$ \\
\hline $\begin{array}{l}\text { Lifetime time horizon } \\
\quad \text { No treatment }\end{array}$ & 54,161 & 8.92 & & & \\
$\quad \begin{array}{l}\text { UAS treatment } \\
\text { Ten-year time horizon }\end{array}$ & 99,357 & 9.94 & 45,196 & 1.02 & 44,446 \\
$\quad$ No treatment & 24,597 & 5.28 & & & 60,216 \\
$\quad$ UAS treatment & 50,189 & 5.70 & 25,592 & 0.42 & \\
\hline
\end{tabular}

ICER, incremental cost-effectiveness ratio; UAS, upper airway stimulation.

a Discounted at $3 \%$ p.a.; all costs are 2016 values.

EUR 60,216/QALY. The total observed cost difference between UAS and no treatment of EUR 45,196 (99,537 vs. EUR 54,161) resulted from UAS index implant costs (EUR 26,184; 58\% of total), UAS replacement costs (EUR $17,639,39 \%$ of total), and baseline health care and maintenance costs (EUR 1,373; $3 \%$ of total).

Sensitivity analyses showed that assumptions about UAS adherence and cardiovascular event risk reduction based on the study-observed AHI changes had the largest effect on the ICER (Fig. 3; online suppl. material). Under the assumption of $100 \%$ therapy adherence, the ICER was reduced to EUR 34,974 per QALY gained. Assuming 50\% cardiovascular event risk reduction as the result of UAS therapy, as opposed to the base case assumption of $75 \%$, increased the ICER to EUR 68,612 per QALY gained. Assuming a 50\% lower baseline MI risk increases the ICER by EUR 1,596 per QALY gained. An assumed shorter battery lifetime increased the ICER (EUR 50,250 per QALY for assumed 9 years of lifetime), while longer battery lifetime lowered it (EUR 40,475 per QALY for assumed 13 years of lifetime). As none of the tested scenarios led to an ICER that would be considered not cost-effective overall, the cost-effectiveness findings were deemed to be robust. For completeness, we assessed the theoretical adherence threshold under which UAS would not be considered cost-effective and found this value to equate $33 \%$. 


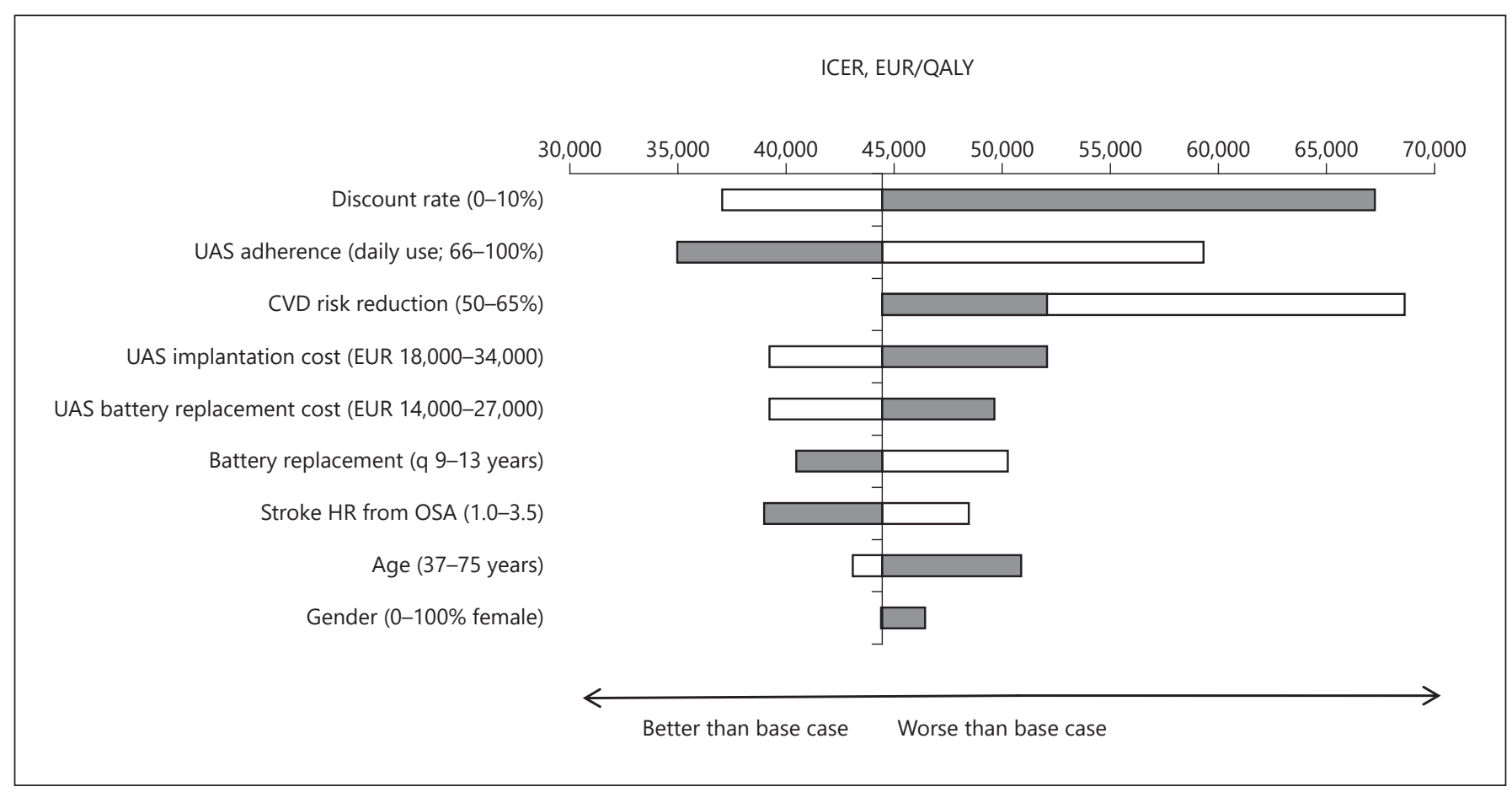

Fig. 3. One-way sensitivity analyses (as tornado diagram) on key model assumptions. The white bar represents the low and the black bar the high value. CVD, cardiovascular disease; HR, hazard ratio; ICER, incremental costeffectiveness ratio; OSA, obstructive sleep apnea; QALY, quality-adjusted life year; UAS, upper airway stimulation.

\section{Discussion}

The long-term projections of clinical benefits and costs associated with UAS treatment of patients with moderate-to-severe OSA who do not qualify for CPAP therapy found UAS to provide meaningful benefit to patients at acceptable costs compared to no treatment. Specifically, our analysis found UAS to add more than 1 year of lifetime concomitant with overall improved healthrelated quality of life.

These findings are generally in line with the earlier cost-effectiveness analysis conducted in the US setting based on the STAR study [15], but add significant new insight. First, our study is based on recent real-world data from a post-market study that reflects practice patterns and patient selection criteria that have been further established in the early years of UAS adoption in clinical practice. Second, our current analysis is based on German incidence and prevalence data of underlying conditions, including hypertension, MI, and stroke incidence, and event rates including MVC incidence, which partly differ from US cohort data. Furthermore, German health care system costs differ substantially from US health care costs, including acute and long-term costs of events that may be avoided or decreased with UAS therapy. It is noteworthy that CPAP adherence over 1 year exceeds $60 \%$ in Germany with polysomnographic therapy adjustment [22]. Studying the effect of these changes on cost-effectiveness is hence particularly relevant to German and European decision makers.

In Germany and other European health care systems not adopting a formal willingness-to-pay threshold for decision making, added patient benefit - as measured by differences in mortality, morbidity, and health-related quality of life - is considered an important criterion in the evaluation of the societal value of new therapies. Our findings show that UAS therapy can be expected to add clinically significant benefit to OSA patients who have exhausted first-line therapeutic options.

These reported benefits stem primarily from the expected long-term event reductions and quality of life improvements associated with a maintained reduction in AHI. Our analysis assumes that therapy effectiveness is maintained over the patient's lifetime at levels observed during 12-month follow-up. This assumption is support- 
ed by the currently available long-term follow-up data from the STAR study, which showed continued therapy effectiveness at the 5-year follow-up at levels comparable to the 12 -month data $[14,23]$. As our sensitivity analyses show, potential changes in long-term therapy effectiveness have a direct effect on clinical outcome and associated long-term costs. While any such changes would therefore alter the projected clinical benefit to patients, the effect on cost-effectiveness is less pronounced. This is, in part, explained by the fact that any increases in survival benefit are also associated with increased baseline health care costs incurred during the additional survival, and that any such survival increases also result in additional clinical events the patients might suffer, which in turn add to cost. Similarly, a reduction in UAS-related survival benefit also results in a concurrent reduction in these types of cost, hence limiting the sensitivity of the ICER metric to changes in long-term therapy effectiveness. However, the findings of this model regarding the long-term cost-effectiveness should be interpreted with caution until further trials confirm long-term maintenance of AHI reduction.

One key difference in the baseline event ratios is the higher MI rate compared to the US. We believe that we used the best data available; therefore, we subjected this parameter to extensive sensitivity analyses. However, even when reducing the MI incidence rate by $50 \%$, the ICER did not change by more than EUR 1,600/QALY, which is likely due to this parameter affecting both treatment groups.

The analysis is subject to a number of limitations. First, as described in the prior UAS model publication, our model is a simplified representation of clinical reality and, as such, may not fully capture all possible patient pathways that might be observed in clinical practice [15]. However, this is a typical and well-accepted limitation of any model-based analysis.

Second, cardiovascular event risk reduction, as discussed earlier, needed to rely on a regression-based analysis and, therefore, is hypothesis based, with some degree of uncertainty. While the study by Marin et al. [24] provides data from a European cohort that shares in many aspects characteristics that are similar to the present cohort, effects in UAS-treated patients might differ from those observed in the Marin study, in which reductions in AHI were based on CPAP therapy. In addition, the study by Marin et al. [25] was not an interventional study. Further, a recent study has challenged the significance of clinical event risk reduction that can be induced by CPAP therapy. Some of these challenges might also apply to
UAS therapy. Nevertheless, there is still wide agreement that effective OSA treatment, as evidenced by a meaningful reduction in AHI, can be expected to be associated with clinically meaningful reduction in long-term events and an improvement in survival. As cardiovascular event reduction was found to have a strong impact on cost-effectiveness of UAS treatment within the conducted sensitivity analyses, more reliable data on the relation of AHI and cardiovascular event rates will facilitate the assessment of the validity of the projected results. In this context, further elucidation of the potential underlying mechanism by which UAS might lower cardiovascular events would be desirable.

Third, the battery lifetime of the UAS implantable pulse generator is estimated based on laboratory testing and simulations only. A lifetime shorter than the assumed 11 years would negatively affect the cost-effectiveness of the UAS treatment, as shown in our sensitivity analysis. Still, even an approximately $20 \%$ shorter battery lifetime would not meaningfully change the cost-effectiveness findings.

Fourth, to calculate QALYs, utility data derived from preference-based quality of life instruments such as the EQ-5D or SF-6D are required. Since both the STAR study and the current German post-market study assessed health-related quality of life using disease-specific nonpreference-based instruments, we needed to rely on health state-specific utility estimates from the published literature. However, the employed utility values have been widely used in OSA-related cost-effectiveness analyses, and the variation in these parameters did not lead to meaningful changes in cost-effectiveness results.

Finally, while the analysis is conducted based on cohort and incidence data that are likely representative for a broader European setting, the cost analysis is based on current data from the German health care system. Due to country-specific variations in UAS device and implantation costs, as well as differences in treatment patterns and costs for cardiovascular events and patient follow-up, our current findings may not be readily transferred to other European health care systems without consideration of the potential effect of differences in underlying cost parameters.

In summary, UAS is a therapy that has previously been shown to be clinically efficacious and that in the present model-based analysis added $>1$ life year or QALY to the remaining life expectancy by reducing, among other events, MIs and MVCs at acceptable costs. Hence, UAS adds meaningful benefit to the health of OSA patients who cannot adhere to CPAP therapy and is a cost-effective treatment strategy in the German health care setting. 


\section{Statement of Ethics}

Given the study type was a model-based analysis, institutional review board approval and patient consent to participate was not applicable.

\section{Disclosure Statement}

The authors maintained the right to publish without approval of the funding source.

\section{Funding Sources}

This study was funded by Inspire Medical Systems, Inc. Wing Tech Inc. (J.B.P., S.L., and B.P.G.) provided health economic consulting. A.-K.R., J.W., and J.B.-S. received funding to support the analyses. A.S. had received funding from Inspire Medical Systems, Inc., for an earlier study (Steffen et al. [14]).

\section{Authors Contributions}

J.B.P., A.-K.R., and J.B.-S. conceived of the study, participated in the study design, data collection, model-based analysis, and drafted the manuscript. B.P.G. participated in the model-based analysis and helped with drafting the manuscript. S.L. participated in the model-based analysis. W.R. and A.S. participated in the study design, critically reviewed the model assumptions, and helped with drafting the manuscript. J.W. critically reviewed the model assumptions and projections and helped with drafting the manuscript. All authors read and approved the final manuscript.

\section{References}

1 Bender B. [Upper Airway Stimulation in OSA]. Laryngorhinootologie. 2016 Nov;95(11):795807.

2 Park JG, Ramar K, Olson EJ. Updates on definition, consequences, and management of obstructive sleep apnea. Mayo Clin Proc. 2011 Jun;86(6):549-54; quiz 554-5.

3 Hofmann F, Birnbaum J. The obstructive sleep apnea syndrome - prevalence and screening in the pre-admission clinic: 5AP42. EJA. 2011 Jun;28:77-8.

4 Peppard PE, Young T, Barnet JH, Palta M, Hagen EW, Hla KM. Increased prevalence of sleep-disordered breathing in adults. Am J Epidemiol. 2013 May;177(9):1006-14.

5 Al Lawati NM, Patel SR, Ayas NT. Epidemiology, risk factors, and consequences of obstructive sleep apnea and short sleep duration. Prog Cardiovasc Dis. 2009 Jan-Feb;51(4):285-93.

6 Kuhn E, Schwarz EI, Bratton DJ, Rossi VA, Kohler M. Effects of CPAP and Mandibular Advancement Devices on Health-Related Quality of Life in OSA: A Systematic Review and Meta-analysis. Chest. 2017 Apr;151(4): 786-94.

7 Mayer G, Fietze I, Fischer J, Penzel T, Riemann D, Rodenbeck A, et al. S3-Leitlinie Nicht erholsamer Schlaf/Schlafstörungen. Somnologie. 2009;13(Suppl 1):4-160.

8 Riachy M, Najem S, Iskandar M, Choucair J, Ibrahim I, Juvelikian G: Factors predicting CPAP adherence in obstructive sleep apnea syndrome. Sleep Breath 2017 May;21(2):295302.

9 Strollo PJ Jr, Soose RJ, Maurer JT, de Vries N, Cornelius J, Froymovich O, et al.; STAR Trial Group. Upper-airway stimulation for obstructive sleep apnea. N Engl J Med. 2014 Jan; 370(2):139-49.
10 Woodson BT, Soose RJ, Gillespie MB, Strohl KP, Maurer JT, de Vries N, et al. Three-Year Outcomes of Cranial Nerve Stimulation for Obstructive Sleep Apnea: The STAR Trial. Otolaryngol Head Neck Surg. 2016 Jan; 154(1):181-8.

11 Heiser C, Maurer JT, Hofauer B, Sommer JU, Seitz A, Steffen A. Outcomes of Upper Airway Stimulation for Obstructive Sleep Apnea in a Multicenter German Postmarket Study. Otolaryngol Head Neck Surg. 2017 Feb;156(2): 378-84.

12 Vanderveken OM, Maurer JT, Hohenhorst W, Hamans E, Lin HS, Vroegop AV, et al. Evaluation of drug-induced sleep endoscopy as a patient selection tool for implanted upper airway stimulation for obstructive sleep apnea. J Clin Sleep Med. 2013 May;9(5): 433-8.

13 Steffen A, Frenzel H, Wollenberg B, Konig IR: Patient selection for upper airway stimulation: is concentric collapse in sleep endoscopy predictable? Sleep Breath. 2015 Dec;19(4): 1373-6.

14 Steffen A, Sommer JU, Hofauer B, Maurer JT, Hasselbacher K, Heiser C. Outcome after one year of upper airway stimulation for obstructive sleep apnea in a multicenter German post-market study. Laryngoscope. 2018 Feb; 128(2):509-515.

15 Pietzsch JB, Liu S, Garner AM, Kezirian EJ, Strollo PJ. Long-Term Cost-Effectiveness of Upper Airway Stimulation for the Treatment of Obstructive Sleep Apnea: A Model-Based Projection Based on the STAR Trial. Sleep (Basel). 2015 May;38(5):735-44.

16 Marin J, Carrizo S. Mortality in Obstructive Sleep Apnea. Sleep Med Clin. 2007;2(4):593601.
17 George CF. Sleep. 5: driving and automobile crashes in patients with obstructive sleep apnoea/hypopnoea syndrome. Thorax. 2004 Sep;59(9):804-7.

18 George CF. Reduction in motor vehicle collisions following treatment of sleep apnoea with nasal CPAP. Thorax. 2001 Jul;56(7): 508-12.

19 Institute of Efficiency and Quality in Health Care (IQWiG): General methods of benefit assessment. 2016. Available from: https://www. iqwig.de/en/methods/methods-paper. 3020.html.

20 Hutubessy R, Chisholm D, Edejer TT. Generalized cost-effectiveness analysis for nationallevel priority-setting in the health sector. Cost Eff Resour Alloc. 2003 Dec;1(1):8.

21 Federal Office of Statistics (Statistisches Bundesamt). Volkswirtschaftliche Gesamtrechnung des Bundes: Bruttowertschöpfung, Bruttoinlandsprodukt. 2017. Available from: www.destatis.de.

22 Galetke W, Puzzo L, Priegnitz C, Anduleit N, Randerath WJ: Long-term therapy with continuous positive airway pressure in obstructive sleep apnea: adherence, side effects and predictors of withdrawal - a 'real-life' study. Respiration; international review of thoracic diseases 2011;82(2):155-61.

23 Strollo PJ, Soose R, Badr M, Strohl KP. 0563 Upper airway stimulation for obstructive sleep apnea: objective and patient reported outcomes after five years of follow-up. Sleep. 2017;40 Suppl 1:A209. 
24 Marin JM, Carrizo SJ, Vicente E, Agusti AG. Long-term cardiovascular outcomes in men with obstructive sleep apnoea-hypopnoea with or without treatment with continuous positive airway pressure: an observational study. Lancet. 2005 Mar;365(9464):1046-53.

25 McEvoy RD, Antic NA, Heeley E, Luo Y, Ou $\mathrm{Q}$, Zhang $\mathrm{X}$, et al.; SAVE Investigators and Coordinators. CPAP for Prevention of Cardiovascular Events in Obstructive Sleep Apnea. N Engl J Med. 2016 Sep;375(10):919-31.

26 Neuhauser H, Thamm M, Ellert U. Blutdruck in Deutschland 2008-2011. Ergebnisse der Studie zur Gesundheit Erwachsener in Deutschland (DEGS1). Bundesgesundheitsblatt. 2013;56(5-6):795-801.

27 Robert Koch Institut (RKI). Daten zu Herzinfarkten in der Region Augsburg: Gesundheitsberichtserstattung des Bundes. 2017. Available from:www.gbe-bund.de.

28 Heidrich J, Wellmann J, Hense HW, Siebert $\mathrm{E}$, Liese AD, Löwel H, et al. [Classical risk factors for myocardial infarction and total mortality in the community-13-year follow-up of the MONICA Augsburg cohort study]. Z Kardiol. 2003 Jun;92(6):445-54.

29 Brown RD, Whisnant JP, Sicks JD, O'Fallon WM, Wiebers DO. Stroke incidence, prevalence, and survival: secular trends in Rochester, Minnesota, through 1989. Stroke. 1996 Mar;27(3):373-80.

30 Hollander M, Koudstaal PJ, Bots ML, Grobbee DE, Hofman A, Breteler MM. Incidence, risk, and case fatality of first ever stroke in the elderly population. The Rotterdam Study. J Neurol Neurosurg Psychiatry. 2003 Mar; 74(3):317-21.

31 Palm F, Urbanek C, Rose S, Buggle F, Bode B, Hennerici MG, et al. Stroke Incidence and Survival in Ludwigshafen am Rhein, Germany: the Ludwigshafen Stroke Study (LuSSt). Stroke. 2010 Sep;41(9):1865-70.

32 Weikert C, Berger K, Heidemann C, Bergmann MM, Hoffmann K, Klipstein-Grobusch $\mathrm{K}$, et al. Joint effects of risk factors for stroke and transient ischemic attack in a German population: the EPIC Potsdam Study. J Neurol. 2007 Mar;254(3):315-21.

33 Mathisen SM, Dalen I, Larsen JP, Kurz M. Long-Term Mortality and Its Risk Factors in Stroke Survivors. J Stroke Cerebrovasc Dis. 2016 Mar;25(3):635-41.
34 Barbé F, Sunyer J, de la Peña A, Pericas J, Mayoralas LR, Antó JM, et al. Effect of continuous positive airway pressure on the risk of road accidents in sleep apnea patients. Respiration. 2007;74(1):44-9.

35 O'Connor GT, Caffo B, Newman AB, Quan SF, Rapoport DM, Redline S, et al. Prospective study of sleep-disordered breathing and hypertension: the Sleep Heart Health Study. Am I Respir Crit Care Med. 2009 Jun;179(12): 1159-64.

36 Yaggi HK, Concato J, Kernan WN, Lichtman $\mathrm{JH}$, Brass LM, Mohsenin V. Obstructive sleep apnea as a risk factor for stroke and death. $\mathrm{N}$ Engl J Med. 2005 Nov;353(19):2034-41.

37 Balk EM, Moorthy D, Obadan NO, Patel K, Ip S, Chung M, et al. Diagnosis and Treatment of Obstructive Sleep Apnea in Adults in Quality AfHRa. Boston (MA): Agency for Healthcare Research and Quality; 2011, Publ No. 11EHC052. p. 494. Available from: http:// effectivehealthcare.ahrq.gov/ehc/ products/117/683/CER432_SleepApnea_ FinalReview_201108.pdf)

38 Baum H, Kranz T, Westerkamp U: Volkswirtschaftliche Kosten durch Straßenverkehrsunfälle in Deutschland. Berichte der Bundesanstalt für Straßenwesen Mensch und Sicherheit 2010;M 208:25-26, 88.

39 Bundesanstalt für Staßenwesen: Volkswirtschaftliche Kosten von Straßenverkehrsunfällen in Deutschland. 2016, 2017. Available from: www.bast.de.

40 Federal Office of Statistics (Statistisches Bundesamt). Unfälle mit Personenschaden, Verunglückte: Deutschland, Jahre, Unfalltyp/ Unfallart, Ortslage, Schwere der Verletzung: Statistik der Staßenverkehrsunfälle. 2017. Available from: www.destatis.de.

41 Kolominsky-Rabas PL, Heuschmann PU, Marschall D, Emmert M, Baltzer N, Neundörfer B, et al. Lifetime cost of ischemic stroke in Germany: results and national projections from a population-based stroke registry: the Erlangen Stroke Project. Stroke. 2006 May; 37(5):1179-83.
42 Grupp H, König HH, Konnopka A. Health care utilisation and costs in the general population in Germany. Health Policy. 2016 Feb 120(2):159-69.

43 Dorenkamp M, Bonaventura K, Leber AW, Boldt J, Sohns C, Boldt LH, et al. Potential lifetime cost-effectiveness of catheter-based renal sympathetic denervation in patients with resistant hypertension. Eur Heart J. 2013 Feb 34(6):451-61.

44 Sullivan PW, Ghushchyan V. PreferenceBased EQ-5D index scores for chronic conditions in the United States. Med Decis Making. 2006 Jul-Aug;26(4):410-20.

45 Glasziou P, Alexander J, Beller E, Clarke P, ADVANCE Collaborative Group. Which health-related quality of life score? A comparison of alternative utility measures in patients with Type 2 diabetes in the ADVANCE trial. Health Qual Life Outcomes. 2007 Apr;5(1) 21.

46 Aasa M, Henriksson M, Dellborg M, Grip L, Herlitz J, Levin LA, et al. Cost and health outcome of primary percutaneous coronary intervention versus thrombolysis in acute STsegment elevation myocardial infarction-Results of the Swedish Early Decision reperfusion Study (SWEDES) trial. Am Heart J. 2010 Aug 160(2):322-8.

47 Grosso AM, Bodalia PN, Macallister RJ, Hingorani AD, Moon JC, Scott MA. Comparative clinical- and cost-effectiveness of candesartan and losartan in the management of hypertension and heart failure: a systematic review, meta- and cost-utility analysis. Int J Clin Pract. 2011 Mar;65(3):253-63.

48 Darlington AS, Dippel DW, Ribbers GM, van Balen R, Passchier J, Busschbach JJ. Coping strategies as determinants of quality of life in stroke patients: a longitudinal study. Cerebrovasc Dis. 2007;23(5-6):401-7.

49 Tousignant P, Cosio MG, Levy RD, Groome PA. Quality adjusted life years added by treatment of obstructive sleep apnea. Sleep. 1994 Feb;17(1):52-60

50 Chakravorty I, Cayton RM, Szczepura A. Health utilities in evaluating intervention in the sleep apnoea/hypopnoea syndrome. Eur Respir J. 2002 Nov;20(5):1233-8.

51 Nyman JA, Barleen NA, Kirdruang P. Quality-adjusted life years lost from nonfatal motor vehicle accident injuries. Med Decis Making. 2008 Nov-Dec;28(6):819-28. 
DuEPublico

Duisburg-Essen Publications online

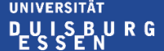

offen im Denken

$U$ | $\begin{aligned} & \text { universitäts } \\ & \text { bibliothek }\end{aligned}$

This text is made available via DuEPublico, the institutional repository of the University of Duisburg-Essen. This version may eventually differ from another version distributed by a commercial publisher.

DOI: $\quad 10.1159 / 000497101$

URN: urn:nbn:de:hbz:464-20220217-143648-5

This publication is with permission of the rights owner freely accessible due to an Alliance licence and a national licence (funded by the DFG, German Research Foundation) respectively. All rights reserved. 